\title{
Influence of diet on dispersal of horse mussel Atrina zelandica biodeposits
}

\author{
Douglas C. Miller ${ }^{1,2, *}$, Alf Norkko ${ }^{1}$, Conrad A. Pilditch ${ }^{2}$ \\ ${ }^{1}$ National Institute of Water and Atmospheric Research (NIWA), PO Box 11-115, Hamilton, New Zealand \\ ${ }^{2}$ Department of Biological Sciences, University of Waikato, Private Bag 3105, Hamilton, New Zealand
}

\begin{abstract}
Benthic suspension feeders repackage particulate matter into organic-rich biodeposits (feces and pseudofeces) that are released into near-bottom flows. Where suspension feeders are found in dense assemblages, they physically alter the near-bottom flow field and thus may affect the local pattern of particle deposition. This dispersal pattern will control the spatial flux of biodeposits, and potential effects on sediment properties and surrounding benthic fauna. We quantified the downstream dispersal of biodeposits produced by an array of horse mussels Atrina zelandica fed either cultured phytoplankton (P) or a mixture of phytoplankton and silt (PS), a diet range that mimics the natural variation in near-bed seston quality. Experiments were run in a laboratory flume at a free-stream velocity of $4.5 \mathrm{~cm} \mathrm{~s}^{-1}$, a value typical of field conditions. Diet had a significant effect on A. zelandica feeding activity and the dispersal of biodeposits. Compared to the P biodeposits, a greater fraction of the PS biodeposits was ejected well above the horse mussel array into the accelerated overlying flow layer (62\% compared with $35 \%$ ). However, more of the PS biodeposits settled either within the $A$. zelandica array or in the $120 \mathrm{~cm}$ working section downstream of the array (43 vs $17 \%$ of P biodeposits). Despite overall similarity in size, PS biodeposits had a settling velocity twice that of the P biodeposits. Of biodeposits settling downstream of the array, more than $70 \%$ settled within $20 \mathrm{~cm}$ of the trailing edge, regardless of diet. The density of biodeposits decreased exponentially with distance from the array at a rate that was similar for both diets. Monte Carlo simulations with a simple boundary layer model generally reproduced this pattern, but also highlighted the importance of initial height above bottom as well as flow complexities in the downstream wake region. Thus, the quality and quantity of $A$. zelandica biodeposits reaching the bed depends on the interaction among behavioral responses to available diet, settling velocity and boundary layer flows. Such interactions should have strong but localized effects on the incorporation of pelagic productivity into the sediments and their consequent impacts on benthic community structure.
\end{abstract}

KEY WORDS: Biodeposits · Bivalve · Benthic-pelagic coupling • Suspension feeding • Atrina zelandica $\cdot$ Diet quality $\cdot$ Boundary layer $\cdot$ Fecal pellets

\section{INTRODUCTION}

Dense assemblages of suspension-feeding bivalves play an important role in coastal ecosystems through their influence on benthic-pelagic coupling and nutri-

*Present address: Graduate College of Marine Studies, University of Delaware, 700 Pilottown Road, Lewes, Delaware 19958-1298, USA. E-mail: dmiller@udel.edu ent cycling (Dame 1996, Wildish \& Kristmanson 1997, Gili \& Coma 1998). Biodeposition in beds of suspensionfeeding bivalves occurs due to their physical modification of bed roughness (Fréchette et al. 1989, Green et al. 1998) and their active filter feeding, which results in non-digested material being excreted as feces and pseudofeces (Jørgenson 1990). Captured particles are rejected before ingestion as pseudofeces or ingested, passed through the feeding structures and gut, and compacted into feces (e.g. Ward \& MacDonald 1996). 
These biodeposits typically differ from the seston particles in aggregate particle size and shape, organic content and cohesive properties (Haven \& Morales-Alamo 1966, Kautsky \& Evans 1987, Dame 1993, 1996). The repackaging of seston into biodeposits induces a downward vertical flux of material from the water column to the seabed. This biologically mediated sedimentation can result in local deposition rates that substantially exceed that of passive physical sedimentation (Verwey 1952, Kautsky \& Evans 1987, Dame 1993). Since biodeposits can be rich in carbon and nitrogen, this material represents a flux of organic matter that will have significant effects on the biogeochemical properties of the sediment in the depositional area (Haven \& Morales-Alamo 1966, Kraeuter 1976, Kautsky \& Evans 1987, Norkko et al. 2001) and will augment the food available to deposit feeding benthic infauna (Newell et al. 1982, Marsh \& Tenore 1990). Graf \& Rosenberg (1997) asserted that such an interception of laterally advected material and the increased influx of organic matter could double the food supplied to the benthos. In dense beds of suspension-feeders or in aquaculture, high rates of biodeposition may result in dramatically increased microbial activity, and reduced anoxic conditions in the sediment (Stoeck \& Albers 2000), leading to benthic communities of low macrofaunal diversity (e.g. Mattsson \& Lindén 1983, Commito \& Boncavage 1989, Dittmann 1995, Kroencke 1996).

Downstream dispersal of biologically repackaged particulate matter has been extensively studied in freshwater lotic systems, especially with respect to fecal pellets produced by blackfly larvae (e.g. Wotton et al. 1998, Fonseca 1999, Wotton \& Malmqvist 2001). High larval abundances and slow settling of pellets result in a considerable downstream flux and transformation of organic-rich particles (Malmqvist et al. 2001). Field and laboratory flume studies have been supplemented by comprehensive modeling work to analyze the role of turbulence and the resulting distributions of travel times and hitting distances downstream (McNair et al. 1997, McNair 2000, McNair \& Newbold 2001).

Marine investigations of biodeposition by bivalve molluscs have focused on mechanisms of production, and on estimating vertical flux rates (Wotton \& Malmqvist 2001). However, vertical flux rate (in mass per unit area per time) is simply a point estimate and does not consider the process of biodeposit dispersal and deposition, which leads to spatial variation in flux rates. Where suspension feeders form dense assemblages, they physically alter the bottom boundary flow and may affect the local spatial pattern of particle deposition (Ertman \& Jumars 1988, Monismith et al. 1990, O'Riordan et al. 1993, 1995, Nepf et al. 1997, Pilditch et al. 1998). Epifaunal species are likely to have the greatest effects on the near-bed flows, and the spatial patterns of deposition are likely to be related to areal density and patch size. Despite the recognized importance of spatial variability in organic matter supply to benthic community structure (e.g. Grassle 1989, Thrush et al. 1989, Olafsson 1992), there are few (if any) estimates of the fraction of the biodeposits retained within a patch of suspension feeders versus that which leaves to deposit downstream. Depending on that balance, a patch may or may not export biodeposits (and associated organic matter), and the patch edge may represent a transition between flux patterns. Likewise, there are few data to suggest how far away from the patch edge effects would be apparent. Biodeposits in marine systems are generally greater in size (being produced by larger suspension feeders) and have faster sinking rates than those produced in freshwater systems (Wotton \& Malmqvist 2001) and should thus deposit relatively close to their source. However, in light of a flow environment that can be dominated by bi-directional, wave and tidal currents interacting with bottom topography, estimating the length scales for dispersal of biodeposits is more complicated in the marine environment.

The horse mussel Atrina zelandica (hereafter referred to as Atrina) is a large (up to $30 \mathrm{~cm}$ long), suspension-feeding pinnid bivalve common in sandy and muddy subtidal environments around the coast of New Zealand (Powell 1979, Cummings et al. 1998). Atrina protrude up to $10 \mathrm{~cm}$ above the sediment surface and have historically formed large patches (e.g. $>10 \mathrm{~m}^{2}$ ) at abundances exceeding 100 ind. $\mathrm{m}^{-2}$ on the seafloor (Cummings et al. 1998, Green et al. 1998). Atrina produce copious amounts of biodeposits (J. E. Hewitt pers. comm.) and modify boundary flow conditions (Green et al. 1998). Hence, Atrina have the potential to influence estuary-wide near-bed hydrodynamics and associated transport, deposition and entrainment of sediments. Since biodeposits may represent spatial subsidies in food supply for benthic animals, measuring the potential for, and scale of, lateral advection of biodeposits is essential to understanding infaunal benthic population and community responses. A previous field study using this suspension-feeding bivalve demonstrated strong site-specific links between biodeposition, sediment biogeochemical characteristics and macrofaunal community structure (Norkko et al. 2001). Higher localized inputs of biodeposits and more diverse and abundant macrofaunal assemblages were found close to individuals and clusters of Atrina compared to bare patches only $30 \mathrm{~cm}$ away. These findings suggest the presence of distinct spatial gradients in biodeposit flux away from the suspension feeders and suggested that local variations in sedimentation could play an important role in explaining some of the patchiness of surrounding benthic communities (Norkko et al. 2001). 
The aims of this study were to quantify biodeposit dispersal from a patch of Atrina in a well-defined flow field and to measure physical and chemical characteristics (i.e. settling velocities, chemical composition) of the biodeposits. Based on a review of the pertinent literature, we predicted biodeposit production and dispersal to be dependent on at least 3 factors: seston composition, suspension-feeder behavior and structure of the near-bottom flows. We conducted pilot studies and determined that all 3 of these factors could be successfully manipulated or quantified in the laboratory using a realistic flows and patch size. We measured flow, observed feeding behavior and production of biodeposits on 2 diets, mapped biodeposit deposition downstream, and quantified biodeposit characteristics.

\section{MATERIALS AND METHODS}

Atrina collection and maintenance. Adult Atrina were collected by SCUBA in December 1999 from a natural population at 4 to $5 \mathrm{~m}$ depth in Mahurangi Harbour $\left(174^{\circ} 44^{\prime} \mathrm{E}, 36^{\circ} 30^{\prime} \mathrm{S}\right)$ situated on the east coast of the North Island, New Zealand. Atrina were scrubbed clean of epifauna, held in an aerated recirculating sea water system for $4 \mathrm{~d}$ at $15^{\circ} \mathrm{C}$ on a $12: 12 \mathrm{~h}$ light:dark cycle, and fed daily with the flagellate Isochrysis galbana before being transferred to the flume. A total of 15 healthy Atrina (i.e. open valves with extended mantle) were selected for subsequent experiments. They averaged $21.4 \mathrm{~cm}$ total length (range 18.5 to $26 \mathrm{~cm}$ ) by $11.0 \mathrm{~cm}$ maximum width (range 9.5 to $12.5 \mathrm{~cm}$ ).

Laboratory flume. Experiments were conducted in a recirculating flume similar to that described by Roegner et al. (1995). Briefly, the flume consisted of a $7.23 \mathrm{~m}$ long, $50 \mathrm{~cm}$ wide, and $50 \mathrm{~cm}$ deep acrylic channel with a $40 \mathrm{~cm}$ diameter return pipe that ran beneath the flume. An impeller in the descending arm of the return pipe regulated flow speed via a variable-speed AC motor. Two flow straightener grids $\left(1 \mathrm{~cm}^{2}\right.$ mesh) were positioned 40 and $52 \mathrm{~cm}$ downstream of the flume entrance, and the floor of the flume was smooth except for the Atrina array described below. The flume was filled to $28 \mathrm{~cm}$ water depth with freshly collected seawater (salinity $=30.9 \%$ ) filtered to $5 \mu \mathrm{m}$, and experiments were conducted at $19^{\circ} \mathrm{C}$.

In the flume, we created a horse mussel array $(85 \times$ $50 \mathrm{~cm}$, starting $365 \mathrm{~cm}$ from the flume entrance, areal density approximately $100 \mathrm{~m}^{-2}$ ) consisting of Atrina shells plus live, actively feeding Atrina for behavioral observations and biodeposit production (Fig. 1). At the downstream end of the array, 15 live Atrina were implanted in a sediment tray insert $(40 \mathrm{~cm}$ long, $50 \mathrm{~cm}$ wide and $15 \mathrm{~cm}$ deep) filled with well-sorted fine quarry sand. These Atrina protruded 10 to $11 \mathrm{~cm}$ above the bed, preserving a height common in field populations. Immediately upstream of the sediment tray and live Atrina, 30 Atrina shells were placed upright in lifelike positions. These shells were collected live from the field, cleaned of mussel flesh and epifauna, filled with concrete cement, and then cut to 10 to $11 \mathrm{~cm}$ shell length. They served to create flow acceleration and turbulence upstream of the live Atrina. Live Atrina were not used in this upstream portion because they could not be implanted in the solid floor. Within the array, distances between individuals and their orientation to the flow were matched to a randomly chosen photograph of a horse mussel patch in Mahurangi Harbour. The entire array was photographed from various angles to document the spatial arrangement of the shells and live Atrina, and the live individuals did not change their positions and heights during the experiments. By using the combination of shells (dead) and live biodeposit-producing Atrina across the whole width of the flume, we were able to simulate flow over a patch comparable in size, structure and density to those in situ (Cummings et al. 2001). This arrangement also made flow as uniform as possible across the flume and allowed us to quantify dispersal of biodeposits produced near the downstream edge of the array. Biode-

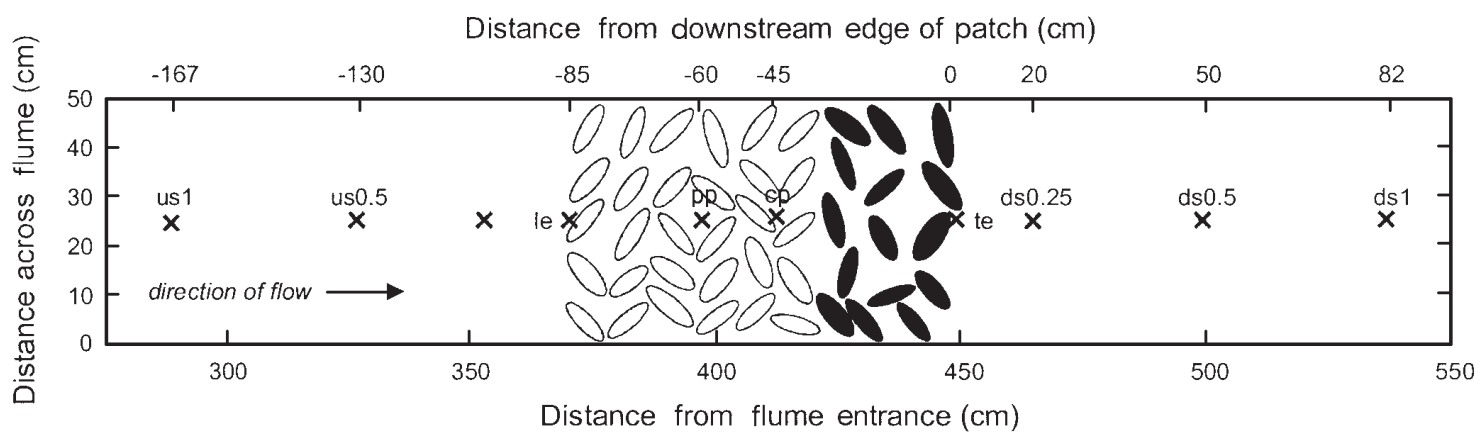

Fig. 1. Diagram of the working section of the flume showing the locations of the flow profiles (crosses with letter designations, see text) and placement of Atrina (ellipses). Solid ellipses: 15 live Atrina; open ellipses: 30 Atrina shells 
posits produced by Atrina here would be those most likely to leave the patch and transport downstream.

The flow we used in the flume had a single freestream velocity of $4.5 \mathrm{~cm} \mathrm{~s}^{-1}$, representative of the mean tidal currents measured above Atrina beds in Mahurangi Harbour (Green et al. 1998). Preliminary trials using this flow speed showed that a well-defined boundary layer was formed in the flume ahead of the Atrina shell array, and that biodeposits were deposited on the smooth floor of the flume downstream of the array, upstream of where water exits the flume. To characterize the flow and boundary layer dynamics in detail, vertical profiles of flow velocity were made at several points along the centerline of the flume using a Sontek 10-MHz Acoustic Doppler Velocimeter (ADV). Profile positions were selected to describe flow upstream ('us') and downstream ('ds') of the Atrina array with distances scaled to fractions of the array length in the along-stream dimension. For example, profile us1 was located 1 patch length $(85 \mathrm{~cm})$ upstream of the leading edge of the array (Fig. 1). We also recorded profiles at the leading edge of the array ('le'), within the array ('pp' and ' $\mathrm{cp}^{\prime}$ ), and at the trailing edge ('te'). Outside the Atrina array, profile measurements were made between 1 and $18 \mathrm{~cm}$ above the flume floor at 9 heights $(z=1,2,3,5,7,10,12,15$ and $18 \mathrm{~cm}$ above bottom, nominally). Above the Atrina, flow profiles began at $9.5 \mathrm{~cm}$ above the flume floor, and measurements were made at 8 heights $(z=9.5,10,11,12,13$, 14,15 and $18 \mathrm{~cm}$ ). At one location in the array ('pp', Fig. 1), the arrangement of Atrina allowed the ADV to penetrate to the bed, permitting 5 additional flow measurements $(z=1,2,3,5$ and $7 \mathrm{~cm}$ above the sand bottom). The minimum height above the flume floor was chosen to insure that the bottom boundary was not included in the ADV sample volume (Finelli et al. 1999). At each height, velocity estimates were collected for $60 \mathrm{~s}$ at $2 \mathrm{~Hz}$. Previous, detailed mapping of the flow in this flume (unpubl.) showed no low frequency variations in flow speed, and that good estimates of mean flow speeds are obtained after 1 min of sampling. Flow measurements were made over several days at the time of our feeding experiments, and the flow settings for the impeller motor and imposed flow proved highly reproducible. Since the Atrina did not change height or orientation, the flow profiles are consistent and comparable between runs and days.

Experimental protocol and diets. In preliminary experiments, using video we were able to track the ejection and dispersal of individual biodeposits from an identified Atrina. At the observed production rates and the single, highly repeatable flow speed chosen, the biodeposits dispersed independently of each other and either settled to the flume floor or were carried in suspension into the return pipe of the flume. Biode- posits that settled to the flume floor did not subsequently fragment, resuspend or move, and because they were sparsely distributed they did not form aggregations. Individual biodeposits could be collected intact by gentle suction with a wide-mouth pipette for further analysis. Biodeposits that entered the return pipe were trapped on the flow rectifiers at the flume entrance and did not recirculate through the array. Thus it proved feasible to study the dispersal of individual biodeposits.

We examined the effect of diet on Atrina feeding behavior, biodeposit dispersal and biodeposit characteristics (size, chemical composition and settling velocity) in 6 experimental runs, with 2 different diets (see below). Four of the runs consisted of $1 \mathrm{~h}$ observation periods of Atrina behavior and initial biodeposit dispersal ( 2 periods per diet). The 2 remaining runs ( 1 for each diet) were conducted over $14 \mathrm{~h}$ to (1) examine downstream dispersal and settlement patterns of biodeposits, (2) measure biodeposit settling velocity, and (3) analyze chemical characteristics of the biodeposits. A greater number of experimental runs was not feasible because of difficulties in maintaining water quality conditions within the flume and ensuring that the mussels remained in a healthy condition. For this reason and the fact that differences in Atrina behavior and biodeposit dispersal were minimal between replicate runs, we chose to focus on individual biodeposits as our experimental unit or replicate.

Specifically, we studied dispersal of biodeposits produced by Atrina feeding on either phytoplankton (P) or a mixed diet of phytoplankton and silt-clay (PS), 2 diets chosen to span the range of seston quality that mussels are likely to experience in situ where resuspension of bottom sediments can alter the characteristics of the seston available for ingestion (Grant 1996). During feeding periods (several hours or overnight, see below) the flow was turned off, the live Atrina were surrounded by a plastic curtain that extended throughout the water column, and the diet was added to this restricted volume; several airstones were placed in the enclosure to prevent sedimentation of the diet. The P diet consisted of $40 \mathrm{ml}$ of Isochrysis galbana culture added to the $90 \mathrm{l}$ enclosure, giving a final concentration of $1.56 \times 10^{5}$ cells ml ${ }^{-1}$ or $5 \mathrm{mg} \mathrm{l}^{-1}\left(3.3 \times 10^{-11} \mathrm{~g}\right.$ cell $^{-1}$, Pilditch unpubl.). The PS diet was prepared by wet-sieving $(<30 \mu \mathrm{m})$ silty sediment from Mahurangi Harbour, and combining this sediment with $40 \mathrm{ml}$ of the algal culture. Adding the silt-clay slurry increased suspended seston concentrations to $250 \mathrm{mg} \mathrm{l}^{-1}$ within the $90 \mathrm{l}$ feeding enclosure.

The first 4 experimental runs were behavioral experiments over a $5 \mathrm{~d}$ period starting with $2 \mathrm{~d}$ of acclimation to the flume. Prior to the experiments, Atrina were fed 
the $\mathrm{P}$ diet overnight to acclimatize to the diet and then again for 2 to $3 \mathrm{~h}$ in the morning to ensure satiation and biodeposit production. The first 2 runs using the $\mathrm{P}$ diet were then conducted by videotaping Atrina behavior and biodeposit dispersal during 2 separate $1 \mathrm{~h}$ periods under flow; the 1st in the morning and the 2nd in the afternoon. The following day, all settled biodeposits within and downstream of the array were removed with a wide-mouth pipette $(0.5 \mathrm{~cm}$ across $)$. The $2 \mathrm{P}$-diet feeding and flow runs were followed by an acclimation period to the new PS diet by twice feeding with the PS diet overnight and allowing sufficient time for gut clearing (gut passage times are several hours, J. E. Hewitt pers. comm.). As with the P diet treatments, the PS diet was added early in the day, after which we recorded 2 separate, $1 \mathrm{~h}$ periods of video, again in the morning and afternoon. Flume flow was maintained overnight for a further $14 \mathrm{~h}$ to allow for gut clearance. Again, all settled biodeposits within and downstream of the array were removed. The Atrina were maintained unfed in the flume flow for the next $3 \mathrm{~d}$.

The last 2 experimental runs were designed to quantify the downstream dispersal of biodeposits produced after feeding upon the 2 diets, P and PS. Although we collected biodeposits produced during behavioral experiments, we found that too few accumulated downstream of the array during the $1 \mathrm{~h}$ observation periods for adequate statistical analysis. Our deposition runs were conducted on 2 consecutive days using the P diet on the first day and PS on the second. During and immediately following feeding, all biodeposits present within and downstream of the array were removed. The flow was restarted and biodeposits were allowed to disperse in the flow and accumulate overnight on the flume floor. We collected all biodeposits from within the live Atrina array, and all of those downstream for our P sample, or enough to reach about 100 for the PS sample (i.e. $>95 \%$ of all deposited). We recorded positions in the cross-stream and downstream directions, and carefully removed biodeposits using a wide-mouth pipette $(0.5 \mathrm{~cm}$ across), measuring the length and width of each biodeposit to $\pm 0.5 \mathrm{~mm}$. The settling velocity of each biodeposit was determined by measuring the fall time in a $50 \mathrm{~cm}$ high $\times 8 \mathrm{~cm}$ diameter glass cylinder filled with seawater, disregarding values if the fall path brought the biodeposit to within $1 \mathrm{~cm}$ of the cylinder's sidewall. Statistical comparisons were made on the size (length and width) and settling velocity of biodeposits collected from both within and downstream of the Atrina array in the 2 treatments (P and PS). The data were tested for normality and homogeneity of variances (Shapiro-Wilk's and Cochran's tests at $\alpha=0.05$, respectively), log-transformed where necessary, and analyzed using ANOVA (Zar 1984). For each diet, individ- ual biodeposits were collected at the bottom of the cylinder, pooled, frozen and analyzed for organic carbon and nitrogen content with a Perkin-Elmer $2400 \mathrm{CHN}$ analyzer.

We used 3 video cameras to track dispersal of biodeposits in the behavioral experiments. Camera 1 was positioned to the side of the flume and focused on the live Atrina to quantify the elevation of release or ejection, and of the initial trajectories of the biodeposits. Camera 2 also recorded from the side, but downstream of the Atrina array. Camera 3 provided an overhead view of the live Atrina to assess their feeding activity. To quantify biodeposit production and dispersal, we analyzed $4 \mathrm{~h}$ of video recordings from each camera (i.e. the two $1 \mathrm{~h}$ recordings immediately following feeding on each of the 2 diets). Images from camera 1 were displayed on a video screen overlaid with a grid, and each biodeposit was associated with a known, individually numbered Atrina. For each biodeposit, we recorded 2 variables. First, the 'sweep point' defined as the height above the bed at which the biodeposit was first moved downstream by the flow. Secondly, for biodeposits forcibly ejected upward by valve closure (readily apparent on the tape), we define the 'ejection distance' as the vertical distance from the Atrina's mantle edge (i.e. where the biodeposit was released) to the sweep point. Distances measured from the screen were corrected for perspective distortion $( \pm 0.5 \mathrm{~cm})$ using the known cross-stream-position of each Atrina and a calibration formula derived from recordings of a $1 \mathrm{~cm}^{2}$ grid pattern at 3 positions across the width of the flume. Our calibration formula was dependent only on the crossstream position, since this dimension accounted for $97 \%$ of the scale variation. Slight discrepancies in numbers of events reported below reflect the fact that in a few instances we observed biodeposit production but were unable to record one of the trajectory parameters. Feeding activity, assessed by the shell gape of each Atrina individual, was estimated from the overhead video (camera 3) by capturing still images every 2 min.

We combined the video data from the two $1 \mathrm{~h}$ observation periods for each diet because these represent feeding and biodeposit production during the period best characterized by our experimental treatments, and together the $2 \mathrm{~h}$ of recording yielded enough biodeposit production events for statistical analysis. It proved impractical to record videos and analyze overnight recordings for production events. The subsequent overnight runs were necessary to yield adequate numbers of deposited biodeposits for our analyses. Consistent with our analysis of individual biodeposit dispersal and settling characteristics, we treated production of biodeposits (i.e. individual ejections) as replicate events for statistical analysis. Differences in Atrina feeding be- 

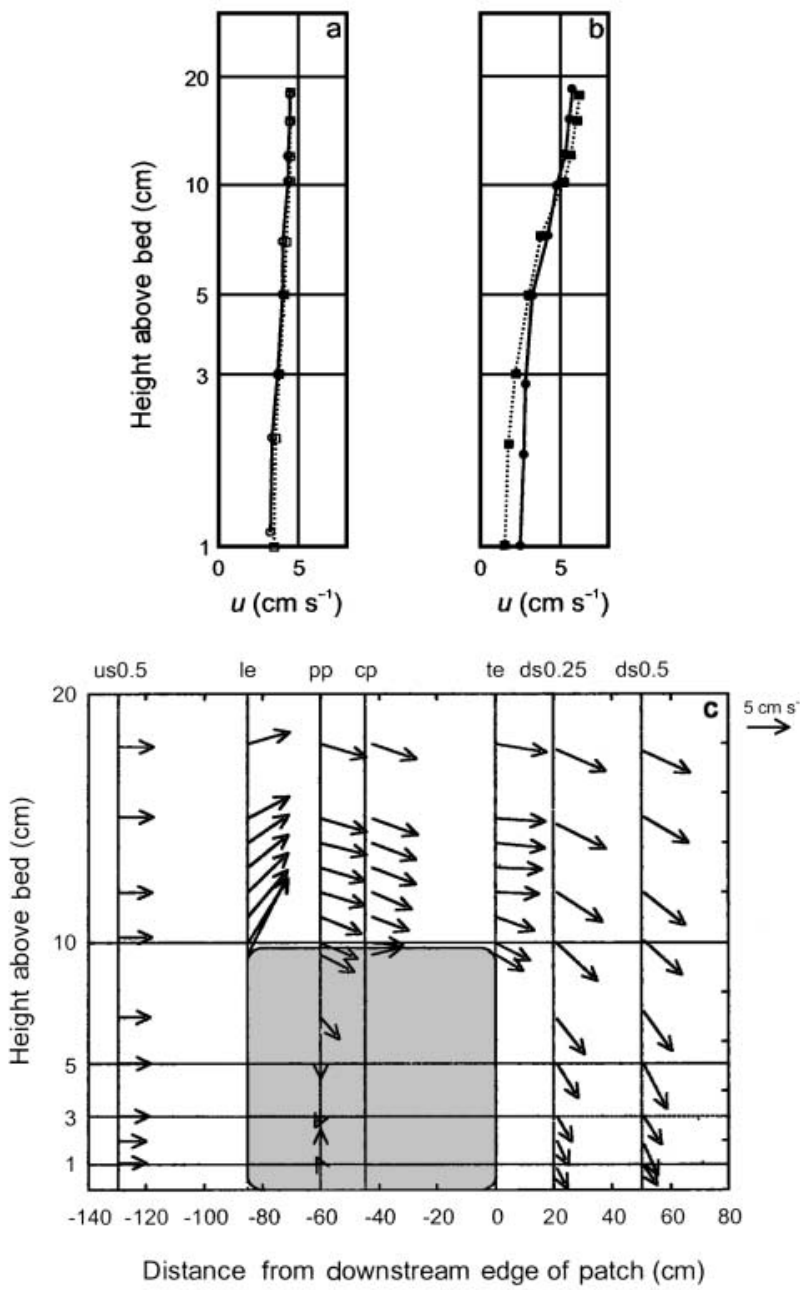

Fig. 2. Flow profiles (a) upstream: us1 (०), us0.5 (ㅁ); (b) downstream ds0.5 (•), ds1 $(\bullet)$; and (c) over the Atrina array (shaded). The upstream (a) and downstream (b) profiles show the variation in flow speed $(u)$ with height above the bed (log scale). Flow velocity above and within the Atrina array (shaded) shown by flow vectors (arithmetic scales). Location of profiles shown in Fig. 1

havior (biodeposit ejection frequency) and dispersal dynamics (the proportion of biodeposits retained or exported from the array and the fraction of biodeposits settling downstream of the array) as a function of diet were also examined statistically.

\section{RESULTS}

\section{Flow conditions}

Vertical flow profiles well upstream of the array (us1 and us0.5, Fig. 1) were used to estimate the imposed flow conditions. Free stream speeds were 4 to $4.5 \mathrm{~cm}$ $\mathrm{s}^{-1}$, and at position us0.5 the shear velocity $\left(\mathrm{u}_{*}\right)$ was $0.18 \mathrm{~cm} \mathrm{~s}^{-1}$ and roughness length $\left(z_{0}\right)$ was $0.00061 \mathrm{~cm}$, both estimated from the regression of velocity versus the natural logarithm of height above the bed (Muschenheim et al. 1986). The straight-line log plots $\left(\mathrm{r}^{2}>0.97\right)$ and the negligible difference in the flow profiles between us1 and us0.5 are indicative of a welldeveloped, approximately logarithmic boundary layer imposed on the array (Fig. 2a). Changes in mean flow (Fig. 2c) are clearly seen as the flow accelerates over the Atrina array in a skimming flow. Since the array extends across the full width of the flume, there is a change in flow depth, and the potential for a change in hydraulic regime. However, tranquil flow was present throughout the flume since Froude numbers are $\leq 0.035$, much less than 1 at which a hydraulic jump to shooting flow would occur (Nowell \& Jumars 1987, Vogel 1994). Flow speeds within the array itself (pp) are greatly reduced $\left(0.5 \mathrm{~cm} \mathrm{~s}^{-1}\right.$ at $z<10 \mathrm{~cm}$, Fig. 2c) compared to the same height at us0.5 $\left(3.8 \mathrm{~cm} \mathrm{~s}^{-1}\right)$, or in the accelerated flow above the array (nearly $6 \mathrm{~cm} \mathrm{~s}^{-1}$ ). Flow profiles over ( $\mathrm{pp}, \mathrm{cp}$, and te) and immediately downstream (ds0.25) of the array show appreciable downward velocity components of up to $0.5 \mathrm{~cm} \mathrm{~s}^{-1}$ (Fig. 2c). Profiles at ds0.5 and ds1 both show appreciable departure from a straight-line log profile, as well as a sizable downward velocity component up to $0.7 \mathrm{~cm}$ $\mathrm{s}^{-1}$ at ds0.5 (Fig. 2c). Compared to the upstream profiles, the downstream flows are greater at a height of $10 \mathrm{~cm}$ (the height of the Atrina) and are reduced below this height, in the lee of the array. These flow differences weaken as the distance downstream increases.

Table 1. Atrina zelandica. Feeding behavior, biodeposit production and initial biodeposit dispersal as a function of diet. $\mathrm{P}=$ phytoplankton diet; PS $=$ phytoplankton + silt diet (means $\pm \mathrm{SD}$; : sample size)

\begin{tabular}{|c|c|c|}
\hline Behavior & $\mathrm{P}$ & PS \\
\hline \multicolumn{3}{|l|}{ Gaping behavior } \\
\hline No. of ind. open & 4 & 8 \\
\hline No. of ind. intermittently open & 11 & 7 \\
\hline No. of ind. closed & 0 & 0 \\
\hline \multicolumn{3}{|l|}{ Biodeposit production } \\
\hline No. of biodeposits & 121 & 81 \\
\hline $\begin{array}{l}\text { No. of ind. producing } \\
\text { biodeposits }\end{array}$ & 13 & 12 \\
\hline $\begin{array}{l}\text { No. of biodeposits ind. }{ }^{-1} \\
\quad \text { (mean; median; range) }\end{array}$ & $\begin{array}{l}9.3 ; 8 \\
1-23\end{array}$ & $\begin{array}{c}6.8 ; 4.5 ; \\
1-38\end{array}$ \\
\hline \multicolumn{3}{|l|}{ Initial biodeposit dispersal } \\
\hline $\begin{array}{l}\text { Mean sweep point } \\
\text { (cm above the bed) }\end{array}$ & $\begin{array}{l}5.2 \pm 2.9 \\
(\mathrm{n}=121)\end{array}$ & $\begin{array}{l}9.3 \pm 3.2 \\
(\mathrm{n}=81)\end{array}$ \\
\hline$t$-test of means & \multicolumn{2}{|c|}{$t=-6.57, \mathrm{p}<0.001$} \\
\hline $\begin{array}{l}\text { Mean ejection distance } \\
\text { ( } \mathrm{cm} \text { above the mantle) }\end{array}$ & $\begin{array}{l}1.7 \pm 0.8 \\
(\mathrm{n}=42)\end{array}$ & $\begin{array}{l}1.6 \pm 0.8 \\
(\mathrm{n}=50)\end{array}$ \\
\hline$t$-test of means & \multicolumn{2}{|c|}{$t=0.68, \mathrm{p}=0.50$} \\
\hline
\end{tabular}


Table 2. Atrina zelandica. Biodeposit dispersal (no., percentage in parentheses) compared by diet: $\mathrm{P}=$ phytoplankton diet $\mathrm{PS}=$ phytoplankton + silt diet. Differ-

\begin{tabular}{|lcccc|}
\hline Biodeposit dispersal & P & PS & $\chi^{2}$ & $\mathrm{p}$ \\
\hline Ejected & $42(34.7)$ & $50(61.7)$ & 14.3 & $<0.001$ \\
Not ejected & $79(65.3)$ & $31(38.3)$ & & \\
Exported from array & $117(96.7)$ & $61(75.3)$ & 21.2 & $<0.001$ \\
Retained within array & $4(3.3)$ & $20(24.7)$ & & \\
Settled downstream & $16(14.2)$ & $11(18.0)$ & 0.45 & 0.501 \\
No settlement & $97(85.8)$ & $50(82.0)$ & & \\
\hline
\end{tabular}
ences examined with a $\chi^{2}$ test

our working section downstream of the array $(\leq 120 \mathrm{~cm})$, did not differ substantially between diets (Fig. 3, Table 2, $\chi^{2}$ test $\mathrm{p}=0.50$ ). Thus the overall result of increased silt in the diet was greater deposition within the array, and consequently fewer biodeposits were exported from the patch. For the $\mathrm{P}$ diet $83 \%$ of the biodeposits left the array and working section, whereas for the PS diet only $57 \%$ left. Biodeposits rarely fragmented after ejection, and even when this occurred the fragments took very similar trajectories downstream. Likewise, occasional biodeposit pieces connected by a nearly transparent mucus filament separated but again took similar downstream trajectories.

\section{Biodeposit production, ejection and export}

All Atrina fed on both diets remained open for at least a part of the observation period, and most individuals ( $\geq 12$ of 15 Atrina) produced biodeposits (Table 1). Video documented that individual Atrina contributed variable numbers of biodeposits and verified that recirculated biodeposits did not bias our data. We confirmed our preliminary observation that ejection and transport of any single biodeposit was independent of other such events (thus, justifiably constituting replicates), and there was no behavioral interference or changes in biodeposit production due to external stimuli. Biodeposits were produced by most of the live Atrina in the array, and hence subsequent dispersal was not biased by release from only 1 or 2 locations in the flume, neither laterally nor with respect to streamwise position.

The sweep point and subsequent dispersal of Atrina biodeposits was strongly affected by diet. Biodeposits produced while feeding on the PS diet began moving downstream at a height nearly twice that of the P diet biodeposits (Table 1, $t$-test $\mathrm{p}<0.001$ ). The difference in sweep points was due in part to a greater fraction of the PS biodeposits being ejected well clear of the Atrina (62 vs $35 \%$ for the $\mathrm{P}$ diet; Table $2, \chi^{2}$ test $\mathrm{p}<$ 0.001). In addition, the $\mathrm{P}$ biodeposits tended to be released as a continuous string that drifted beneath the mantle edge before detachment. Although the rates of biodeposits ejected differed between diets, the mean ejection distances were similar (Table 1). Despite the fact that PS biodeposits had higher sweep points, there was an 8 -fold increase in the proportion retained within the array ( 25 vs $3 \%$ retained; Table $2, \chi^{2}$ test $p<$ 0.001, Fig. 3).

Biodeposits took highly variable paths as they were swept downstream in turbulent flows. The percentage of total biodeposits settling to the flume bottom within
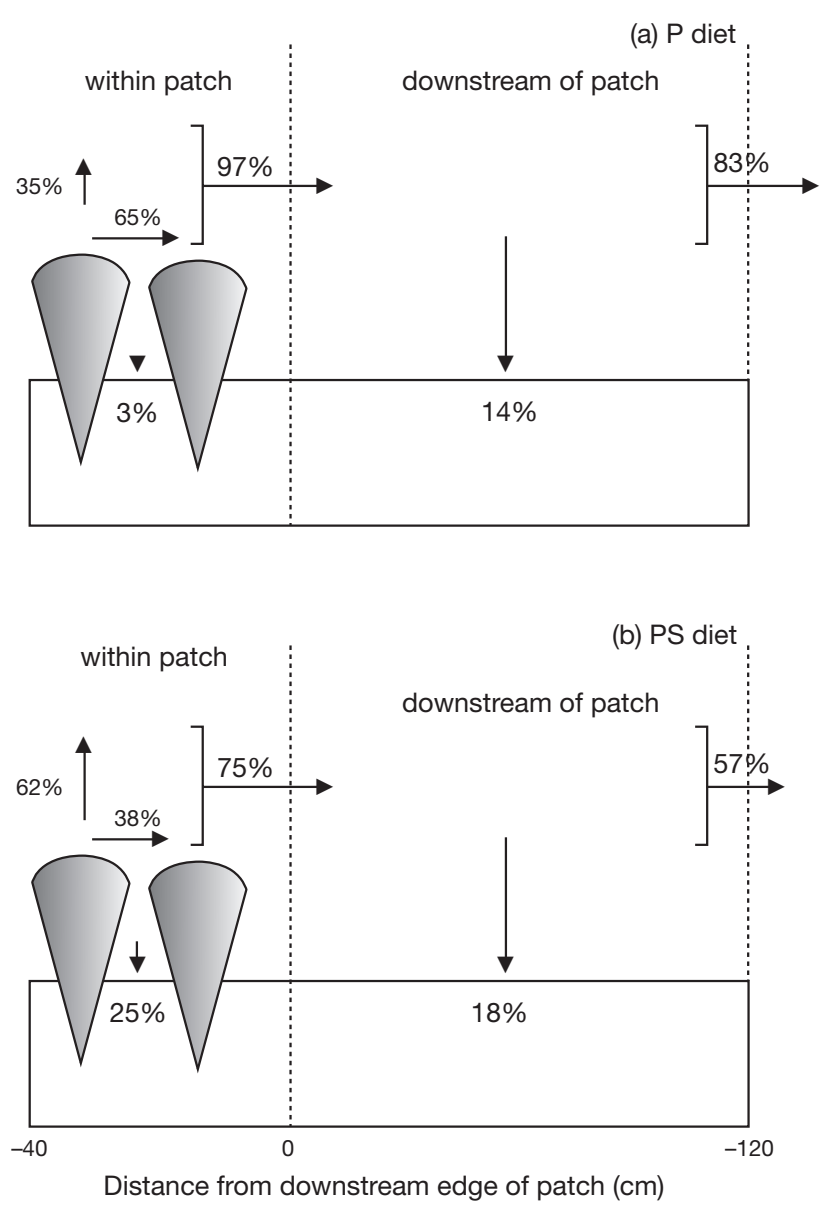

Fig. 3. Atrina zelandica. Graphical summary of source and fate of biodeposits after feeding on (a) phytoplankton (P) and (b) phytoplankton + silt (PS). Values are \% of the events observed on videotapes (summarized in Table 2). Horizontal arrows show direction of biodeposit transport; upward arrows represent ejection of biodeposits by A. zelandica (shaded cones), and downward arrows indicate settling to the flume floor 


\section{Settling and organic properties of biodeposits}

For both diets, most overnight biodeposits (>70\%) were found within $20 \mathrm{~cm}$ of the trailing edge of the array, and the numbers fell off exponentially with distance downstream (Fig. 4). This pattern is remarkably similar for both diets. Although the decrease in biodeposit density with distance downstream appeared slightly more rapid for the PS diet, as indicated by the slopes of the ln transformed data $\left(0.025 \mathrm{vs} 0.021 \mathrm{~cm}^{-1}\right)$, they were not significantly different $(p>0.5, t$-test of slope differences, Zar 1984).

No significant differences in biodeposit size (length or width) could be detected either with location (i.e. inside vs downstream of the Atrina array) or between diets $(\mathrm{p}>0.05$, Table 3$)$. However, settling velocities were significantly different $(p<0.05)$ between location and diet groups with corresponding values for the PS diet biodeposits almost twice as high (Table 3). There was no correlation between biodeposit size (expressed as area, i.e. length $\times$ width) and settling velocity for

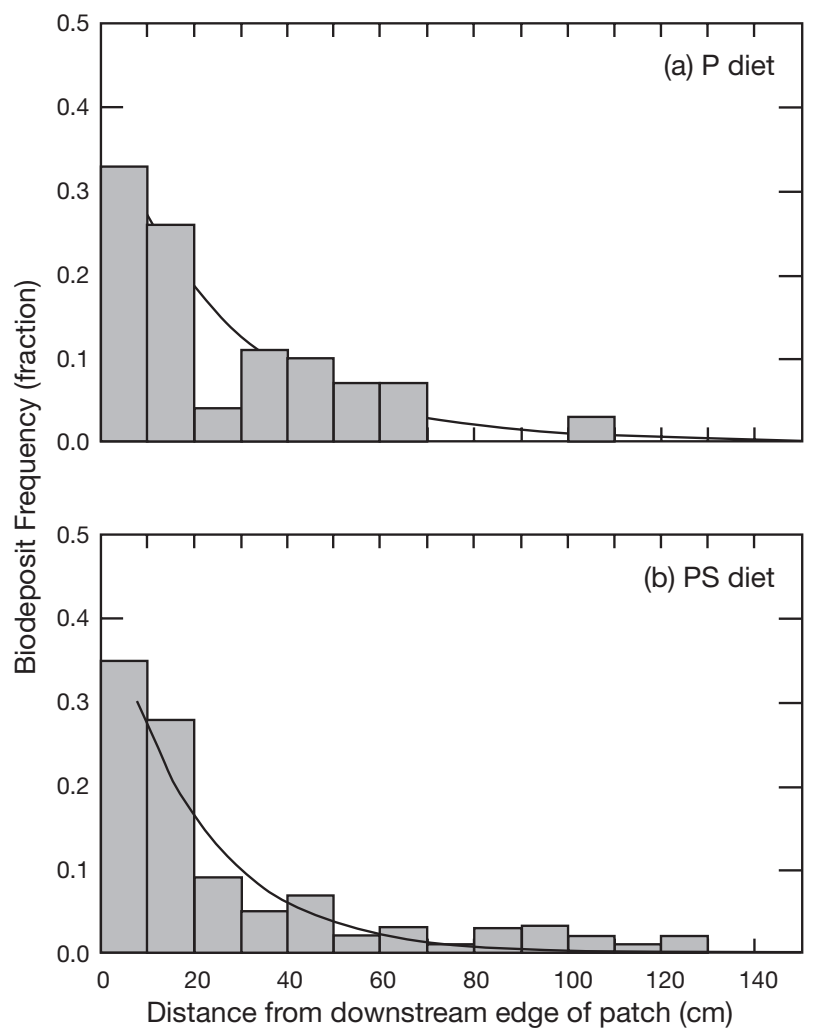

Fig. 4. Atrina zelandica. Downstream distribution of biodeposits measured after feeding on (a) phytoplankton (P) and (b) phytoplankton + silt (PS). Lines represent an exponential fit. Regression statistics, $\mathrm{P}$ diet: $\ln$ (biodeposit frequency) $=$ -1.47 - downstream distance $(\mathrm{cm}) \times 0.021\left(\mathrm{r}^{2}=0.63, \mathrm{p}<0.02\right.$, $\mathrm{n}=8)_{i}$ PS diet: $\ln$ (biodeposit frequency) $=-1.63-$ down stream distance $(\mathrm{cm}) \times 0.025\left(\mathrm{r}^{2}=0.71, \mathrm{p}<0.01, \mathrm{n}=13\right)$ either diet $\left(\mathrm{r}^{2}=0.0001, \mathrm{p}=0.48\right.$, and $\mathrm{r}^{2}=0.005, \mathrm{p}=$ 0.239 for $\mathrm{P}$ and PS, respectively). However, for both diets, there was a significant $\left(r^{2}=0.1, p<0.05\right)$, albeit weak, negative relationship between settling velocity and distance downstream of the array. The negative slope is expected since faster sinking biodeposits should settle closer to the array. From our videotapes, we saw no consistent differences in shape or size of the biodeposits, and we could not distinguish feces from pseudofeces. However, the chemical composition of biodeposits reflected the diet: $\mathrm{P}$ biodeposits had 3 times more organic carbon and nitrogen by weight than those produced on the PS diet (Table 3).

\section{DISCUSSION}

\section{Flume flow and effects of Atrina array}

The Atrina array in the flume was designed to have: (1) an upstream section, (2) a section with only shells to simulate a field-sized patch and generate skimming flow, (3) live Atrina in a smaller section to study biodeposit production and trajectories, and (4) a downstream deposition section of sufficient length for deposition similar to that we observed in the field. We considered the dynamical and practical constraints of experiments using a steady but nonuniform and growing boundary layer, and matched flume to field conditions as closely as possible, to ensure proper scaling and dynamical similarity (Nowell \& Jumars 1984, 1987). We determined the experimental setup based on field studies

Table 3. Atrina zelandica. Characteristics (mean $\pm \mathrm{SD}$ ) of overnight biodeposits inside and downstream of the mussel array. $\mathrm{P}=$ phytoplankton diet; $\mathrm{PS}=$ phytoplankton + silt diet. Chemical properties determined on pooled samples. ANOVA among means showed no significant differences ( $p>0.05$ ) among biodeposit lengths or widths; all 4 settling velocities differ significantly from each other $(\mathrm{p}<0.05)$

\begin{tabular}{|c|c|c|}
\hline $\begin{array}{l}\text { Biodeposit } \\
\text { characteristics }\end{array}$ & $\mathrm{P}$ & PS \\
\hline \multicolumn{3}{|c|}{ Length of biodeposits (mm) } \\
\hline Inside & $14.6 \pm 8.9 \quad(\mathrm{n}=11)$ & $11.1 \pm 10.1(\mathrm{n}=24)$ \\
\hline Downstream & $11.5 \pm 11.8(\mathrm{n}=62)$ & $10.5 \pm 9.0 \quad(\mathrm{n}=88)$ \\
\hline \multicolumn{3}{|c|}{ Width of biodeposits (mm) } \\
\hline Inside & $3.5 \pm 0.7$ & $3.2 \pm 0.6$ \\
\hline Downstream & $3.4 \pm 1.0$ & $3.4 \pm 0.7$ \\
\hline \multicolumn{3}{|c|}{ Settling velocity $\left(\mathrm{cm} \mathrm{s}^{-1}\right)$} \\
\hline Inside & $1.7 \pm 0.8$ & $3.0 \pm 1.3$ \\
\hline Downstream & $1.1 \pm 0.6$ & $2.0 \pm 1.2$ \\
\hline POC (\%) & 20.9 & 6.2 \\
\hline PON (\%) & 2.7 & 0.9 \\
\hline $\mathrm{C}: \mathrm{N}$ ratio & 7.7 & 6.9 \\
\hline
\end{tabular}


(Green et al. 1998), previous studies in this flume, and our preliminary observations with Atrina in the trial runs. By placing a limited number of live Atrina at the downstream end of the array we ensured that biodeposits were produced at a rate that allowed each event to be treated independently. This positioning of the live Atrina also maximized the potential for export from the array so that length scale for dispersal and potential impacts on the surrounding benthos could be assessed.

Our analysis of flow profiles upstream, amid, and downstream of an Atrina array (Figs. 1 \& 2) concurs with that of Green et al. (1998) that Atrina add significant flow disruption and roughness to the bed and have strong influences on near-bed flow. The wake region immediately downstream of the array is a zone of complex flows that extends at least $85 \mathrm{~cm}$ downstream (Fig. 2b,c). Even though only one flow speed was used, our results illustrate how biodeposit dispersal is related to diet quality and feeding behavior under realistic flow conditions.

We used flow depths deeper than normally recommended for the dimensions of our flume (Nowell \& Jumars 1984, 1987, Muschenheim et al. 1986) to cover the upright Atrina and allow ejection of their biodeposits without interference from the water surface. As a consequence, a boundary layer was not fully developed before the leading edge of the Atrina array. Using standard formulas (Nowell \& Jumars 1987, Vogel 1994) and $u_{*}$ measurements at u0.5 and $u 1$, we calculated the thickness of the turbulent boundary layer to be around $12 \mathrm{~cm}$, comparable to that of the Atrina array height (10 to $11 \mathrm{~cm})$. Indeed, the 2 upstream flow profiles are very similar and approximately logarithmic (Fig. 2a), and we used them to characterize the imposed flow in terms of shear velocity and freestream flow. The profiles (mean downstream speeds) from 12 to $18 \mathrm{~cm}$ above bottom are uniform to $<2.3 \%$ and are a valid estimate of the freestream flow speed. Over the array, water accelerates well above the freestream speed and is displaced in skimming flow higher than the predicted boundary layer. The detailed structure of the boundary layer flow upstream of the Atrina is of little consequence to the skimming flow above or the turbulent wake just downstream, which is the region of interest in our experiments.

There was no evidence of strong secondary flows from either the videos of biodeposit trajectories or cross-stream flow vectors measured down the centerline. Because our experiments were conducted over several days, it was more important that the imposed flow was repeatable and that neither Atrina shells nor live individuals moved. This was verified over the course of our experiments and depositional runs, and no temporal changes in either skimming flow or wake regions were detected throughout the experiments. We required reproducibly identical flow conditions for the different feeding treatments, because flow itself, or in combination with food concentration as flux, has been related to effects on feeding and growth of suspension feeders (Lenihan et al. 1996, Finelli et al. 2002). Any differences between diets in biodeposit characteristics, production or behavior can thus be ascribed to diet treatment differences.

\section{Diet effects on biodeposit production}

Atrina produced biodeposits on both experimental diets (Table 1) that spanned the natural range of seston quality. Increased concentrations of sediments (particularly silt and clay) in the seston can significantly increase the production of pseudofeces (e.g. Robinson \& Langton 1980, Iglesias et al. 1992) and change both the quantity and quality of biodeposits. Hewitt et al. (unpubl.) found that 93 to $95 \%$ (dry wt) of all the biodeposits produced were pseudofaeces when Atrina fed on both natural seston (20 to $30 \mathrm{mg} \mathrm{l}^{-1}$ ) as well as on silt/clay additions (up to $600 \mathrm{mg} \mathrm{l}^{-1}$ ). Atrina similar in size to those used in our flume experiments had typical biodeposition rates of 5 to $30 \mathrm{mg}$ dry wt ind..$^{-1} \mathrm{~h}^{-1}$, depending on seston concentration. Moreover, the Atrina in these experiments were highly selective, rejecting most of what they filtered as pseudofeces, which were produced in copious amounts under high seston concentrations. The diets were chosen to represent variations in diet quality expected in the field, where phytoplankton are at times diluted with low food quality silt from resuspended bottom sediments or terrestrial input. Therefore, most of the biodeposits produced on the PS diet were probably pseudofaeces, as shown by their chemical properties (Table 3).

A greater fraction of biodeposits produced on the PS diet was ejected into the overlying flow (62 vs 35\%, Table 2, Fig. 3). This represents an important behavioral response to diet treatments. Our observations cannot determine whether filtration rates were lowered, more effort was placed in rejecting silt particles, ingested particles passed more slowly through the gut, or even whether more pseudofeces were produced relative to feces. However, most of the PS biodeposits were ejected well above the Atrina array by a sharp contraction of the valves rather than being released from the valve margins. Flow acceleration and steep velocity gradients (Fig. 2c), over the array mean that a small variation in release height will affect the distance of transportation downstream. Although the PS biodeposits were ejected to higher sweep points, they were 8 times more likely to deposit within the Atrina array (Fig. 3). While almost all of the $\mathrm{P}$ biodeposits went 
downstream, only $3 / 4$ of the PS biodeposits were exported from the array.

Biodeposits produced on the PS diet fell twice as fast as those produced on the P diet (Table 3). Based on length and width measurements, there was no difference in biodeposit size between diets, nor was there any strong correlation between settling velocity and size measurements for either diet. If settling velocity largely determines settling location, biodeposits that settle faster should be deposited nearer the trailing edge of the array, i.e. there should be a negative correlation between settling velocity and distance downstream. We found only a weak correlation of downstream distance with settling velocity for either diet, suggesting that other variables are important (e.g. sweep point, turbulence, downward velocity components; see 'Modeling biodeposit dispersal in simple boundary layers' below).

Our measurements on suspension-feeder biodeposits can be compared to those made by Taghon et al. (1984) for pellets of the deposit-feeding polychaete Amphicteis scaphobranchiata inhabiting muddy sediments. Pellets are ejected into the overlying flow and travel downstream before depositing on the bed. The polychaete feces were rod shaped and smaller (mean length $=0.6 \mathrm{~cm}$, diameter $=0.15 \mathrm{~cm}$ ) than those produced by Atrina, although their mean settling velocity was up to 2 times higher. Taghon et al. (1984) also found that diet quality influenced biodeposit settling velocity. This emphasizes the difficulty in predicting settling rate and ultimately flux from biodeposit size alone.

\section{Downstream pattern}

The overnight accumulations fell into a simple pattern of an exponential decrease with distance from the trailing edge (Fig. 4). For both diets, $70 \%$ of the biodeposits settled within $20 \mathrm{~cm}$ of the array's trailing edge, and the remaining deposits were distributed thinly further downstream (Fig. 4). Overall, the deposition patterns for the 2 diets were remarkably similar despite the differences in sweep point (Table 1) and settling velocity (Table 3), i.e. the higher ejection points for the PS biodeposits caused by forceful ejection largely compensates for the faster settling (see next section). This pattern is a result of deposition of biodeposits produced just upstream in the Atrina array. There were very few biodeposits $(<2 \%)$ that we could not attribute to a particular Atrina in our video observations, and biodeposits not settling in the downstream camera 2 section settled in other parts of the flume or were trapped on the flow rectifiers. In the field, Atrina are often found in tidal channels with reversing tidal flows, and we expect biodeposits to accumulate on 2 sides of the patch.
Reworking of biodeposits after deposition did not occur in our experiments. Video confirmed that once settled on the flume floor, biodeposits did not move or fragment, nor did they recirculate through the flume and bias our results. Much greater flow velocities are needed to erode the biodeposits and flush them from the working section of the flume. (Pilditch unpubl.). The pattern of initial deposition we documented here should be found in the field under typical tidal flow conditions. When much higher flow speeds are encountered (a case beyond the scope of our work), the biodeposits will probably be resuspended in fragments and with altered physical and chemical properties, depending on their age (see Nowell et al. 1981, Taghon et al. 1984, J. Grant pers. comm.).

We designed our array with the live, biodeposit producing Atrina at the downstream end to study export and deposition in the lee of a patch. Water flow is necessary for biodeposit export from an Atrina patch: observations without flow showed that all feces and pseudofeces were deposited within the patch. From our videotape observations and flow measurements, we expect that biodeposits produced by Atrina farther upstream would deposit in the array. Flow speeds within the array itself were much lower than above it (Fig. 2c) and a biodeposit that falls below the skimming flow or is entrained downward in turbulence, will be retained inside the array. Higher flows would sweep biodeposits further downstream, but might also lead to increased biodeposition in the wake region, which would also extend farther downstream. These predictions should be verified in future flume experiments.

\section{Modeling biodeposit dispersal in simple boundary layers}

There are several models of the transport of biogenic particles, fecal pellets, other biodeposits or larvae. They all start with some basic input parameters, typically initial height of the particle off the bed and its settling velocity, combined with an approximation to the velocity field in a turbulent boundary layer. The 2 calculated parameters of primary interest here are time and distance to contact with the bottom (e.g. McNair et al. 1997, Fonseca 1999, McNair 2000, McNair \& Newbold 2001). Results may be provided in terms of power-law relationships (e.g. Fonseca 1999), distributions of values based on a probabilistic model (McNair et al. 1997, McNair 2000, McNair \& Newbold 2001), or numerical simulations of advection-diffusion equations (e.g. Eckman 1990, Gross et al. 1992, Eckman et al. 1994). Results generally confirm the strong dependence of settling time or distance on initial height above the bottom and the particle's settling 
velocity. Model results may also account for bottom roughness and near-bed turbulence, but only for a bed that is smooth and flat or composed of uniform roughness elements.

We developed a simple Monte Carlo simulation of the ejection and transport of Atrina biodeposits downstream and their subsequent contact with the bed. If the biodeposits are released at a given height above the bottom $\left(z_{\mathrm{h}}\right)$ into a horizontal flow and fall with a vertical settling velocity $\left(w_{\mathrm{s}}\right)$, then the distance between the release point (our 'sweep point') and deposition to the bed $\left(x_{\mathrm{d}}\right)$ is given by:

$$
x_{\mathrm{d}}=\frac{\bar{u} z_{\mathrm{h}}}{w_{\mathrm{s}}}
$$

where $\bar{u}$ is the vertically averaged flow speed from the release point down to the bottom. This relationship holds true regardless of the shape of the flow profile (e.g. logarithmic or perturbed; Fig. 2a,b) and it is approximately true as long as the profile changes only slowly in the along-stream direction. We assume that the horizontal flow speed at a given height above the bed $\left(u_{\mathrm{z}}\right)$ can be described by a log boundary layer:

$$
u_{z}=\frac{u_{*}}{\kappa} \ln \left(z / z_{0}\right)
$$

where $u_{*}=$ bed shear velocity, $z_{0}=$ roughness length scale and $\kappa=$ von Karman's constant (taken to be 0.41 ). This is a rough approximation based on departures from straight-line log plots in Fig. 2b, although this flow profile is the proper downstream limiting case for our flume. The mean flow speed between the bed (actually $z_{0}$, where log layer flow reaches zero) and $z_{\mathrm{h}}$ is:

$$
\bar{u}=\frac{u_{*}}{\kappa\left(z_{\mathrm{h}}-z_{0}\right)}\left[z_{\mathrm{h}} \ln \left(\frac{z_{\mathrm{h}}}{z_{0}}\right)+\left(z_{\mathrm{h}}-z_{0}\right)\right]
$$

Using Eqs. (1) \& (3), we can examine the effects of near bed flow speed, biodeposit ejection height and fall velocity on dispersal distance.

We ran Monte Carlo simulations of Eq. (1) with the input variables constrained by our flume, video and settling chamber measurements to verify the exponential relationships in Fig. 4. Specifically, we used a boundary layer characterized by the upstream $u_{*}=$ $0.18 \mathrm{~cm} \mathrm{~s}^{-1}$ and a $z_{0}=0.00061 \mathrm{~cm}$ (measured at us 0.5 , Fig. 2a). We generated 5000 random vertical release points normally distributed with a mean and standard deviation as given in Table 1. In a similar manner, 5000 settling velocities were produced, based on the values obtained for biodeposits collected downstream of the patch (Table 3). Because we have no data correlating sweep point and settling velocity, these random variables are statistically not correlated in our model. The downstream dispersal distance $\left(x_{\mathrm{d}}\right)$ was corrected for a random release point (by subtracting a distance between 0 and $25 \mathrm{~cm}$ from $x_{d}$ ) within the sector with live Atrina.

The model predicts that peak deposition will be 0 to $10 \mathrm{~cm}$ downstream of the Atrina array (Fig. 5) and nearly $70 \%$ of the biodeposits will accumulate within $20 \mathrm{~cm}$ of the array, similar to the results observed in the flume (Fig. 4). However, the model predicts no deposition in after $80 \mathrm{~cm}$, whereas in the flume biodeposits were found up to $130 \mathrm{~cm}$ downstream. This difference is probably related to the simplistic representation of the flow field in the model (compare with Fig. 2b). Biodeposits released higher in the flume boundary layer actually travel further, because due to flow acceleration over the patch the modeled boundary layer underestimates mean flows in this region. This should account for differences in downstream dispersal.

The pattern of downstream deposition is similar between the flume (Fig. 4) and the model (Fig. 5), both exhibiting an exponential decrease downstream from the region of peak deposition. Given that the modeled biodeposits did not extend as far downstream, the slope of this decline was approximately 3 times steeper

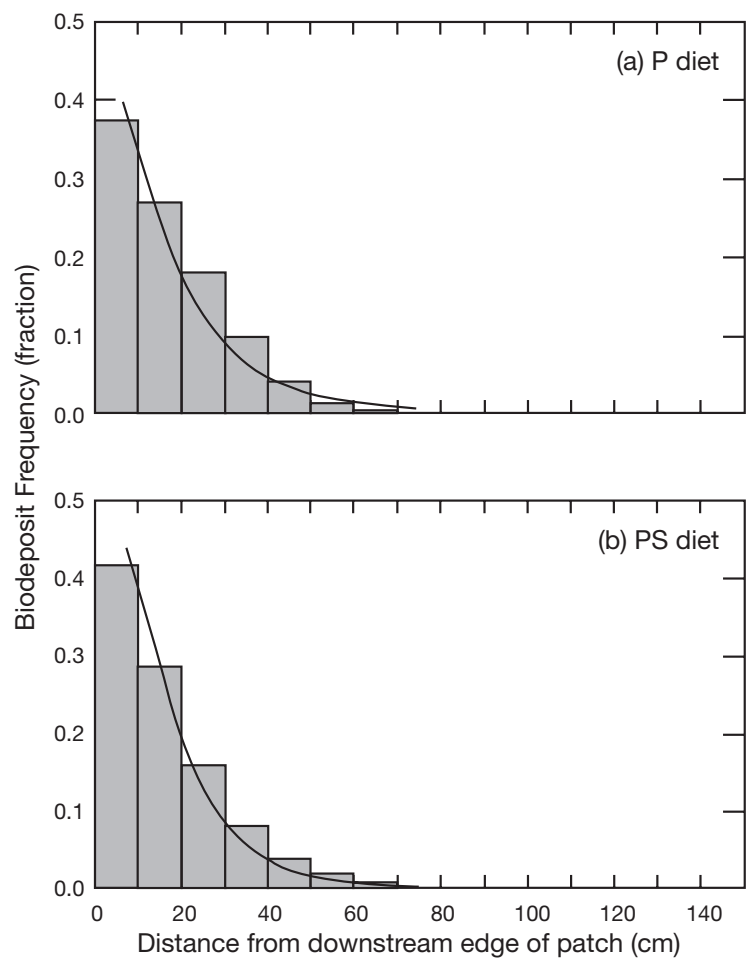

Fig. 5. Atrina zelandica. Downstream distribution of biodeposits predicted by a simple dispersal model of biodeposits produced by feeding on (a) phytoplankton (P) and (b) phytoplankton + silt (PS). Lines represent an exponential fit. Regression statistics, $\mathrm{P}$ diet: $\ln$ (biodeposit frequency) $=-0.24$ - downstream distance $(\mathrm{cm}) \times 0.069\left(\mathrm{r}^{2}=0.97, \mathrm{p}<0.001\right.$, $\mathrm{n}=8$ ); PS diet: $\ln$ (biodeposit frequency) $=0.08-$ downstream distance $(\mathrm{cm}) \times 0.083\left(\mathrm{r}^{2}=0.94, \mathrm{p}<0.001, \mathrm{n}=8\right)$ 
than that observed in the flume. As in the flume, the decrease in abundance for the modeled data was slightly higher for the PS diet (PS slope $=-0.083$ vs $\mathrm{P}$ slope $=-0.069$ estimated by linear regression on $\ln$ transformed data). The ratio of the slopes (PS:P) for the modeled distribution $=1.20$ and for the flume observations $=1.19$ is remarkably similar and may reflect the dependence of the slope (i.e. curvature) on the mean settling velocity. Additional model runs showed that a fixed release point (e.g. $7 \mathrm{~cm}$, an average for both diets, Table 1) yielded very different downstream distribution patterns for the 2 diets. Thus, even though the PS biodeposits settle faster and should be retained close to the array, the fact that their release points are higher offsets this. In practice, the downstream distribution of PS biodeposits is more similar to those of the P diet than would be expected from considering either settling or release alone.

Although this simple model largely predicts the dispersal pattern, extrapolation to other conditions is not justifiable. More realistic flow fields, including the wake region itself (Fig. 2b,c), could be included in the model, albeit at much greater computational cost. Similarly, heavier biodeposits ejected into the water column are likely to travel further due to accelerated flow over the array (compare flow profiles in Fig. 2). Given the steep gradients in flow speed above the Atrina array (Fig. 2c), the distribution of sweep points relative to the top of the array could greatly affect downstream dispersal. This was partly included in the model using the random release height $\left(z_{\mathrm{h}}\right)$ but with a log boundary layer (Eq. 2) lacking the steep velocity gradients we measured above the array (Fig. 2c). There could be a correlation between sweep point or ejection distance, and settling velocity, and this would have strong effects. For example, lighter biodeposits would settle closer to the array if released lower in the flow. It was apparent from video camera 2 that more than half of the biodeposits were transported out of the working section (cf. Fig. 3), whereas we were able to measure settling velocities from biodeposits only within this section, and thus our sample is statistically selfcensored. Clearly, the settling velocity distribution of all biodeposits would be needed before different flow velocities can be modeled. Despite the shortcomings recognized here in terms of the boundary layer and truncated distribution of settling rates, this simple modeling approach can guide future flume experiments or field studies on Atrina beds.

\section{Ecological effects of biodeposit dispersal}

Atrina is a large suspension-feeding bivalve producing significant amounts of biodeposits. Density manip- ulation experiments and surveys have demonstrated significant effects of Atrina on surrounding macrobenthic communities, although the strength and direction of these effects varied in space and time (Cummings et al. 1998, 2001, Thrush et al. 2001). Nevertheless, local hydrodynamic conditions and the spatial arrangement of individuals within Atrina beds were important variables explaining site differences, suggesting that local patterns of biodeposit influx play an important role in affecting surrounding macrofaunal communities. This was verified by Norkko et al. (2001), who found approximately 25 to $30 \%$ higher rates of sedimentation and organic-rich biodeposit inputs within $10 \mathrm{~cm}$ of Atrina individuals and patches compared to only $30 \mathrm{~cm}$ away. Seafloor sediments close to Atrina were enriched in carbon and nitrogen and had more diverse and abundant macrofaunal assemblages that were generally dominated by deposit feeders, demonstrating a strong link between localized inputs of biodeposits and benthic community structure. However, the importance of this interaction decreased with increasing background sedimentation, possibly because the high rates of deposition of poor quality sediment produce dilution rather than enrichment. We found that more biodeposits were retained within the array when silt was incorporated into the diet (Fig. 3). However, these higher rates of biodeposition represented inputs with low organic carbon and nitrogen (Table 3) resulting in potentially negative ecological feedback mechanisms between the diet of the suspension feeder and the surrounding benthic ecosystem.

The overnight deposition patterns we observed in the flume matched those determined with small sediment traps in the field (Norkko et al. 2001). In both studies higher deposition patterns were found in the immediate vicinity of the Atrina compared to further away (Figs. 3 \& 4). In freshwater lotic systems, the downstream dispersal of fecal pellets produced by blackfly larvae (e.g. Wotton et al. 1998, Fonseca 1999) has been given considerable attention. Because of the high density of individuals on the stream bed, the small size and settling rate of the pellets, and strong, steady channel flows, blackfly larval feeding and pelletization represent an important transformation and downstream flux of organic matter in streams and rivers over considerable distances (Malmqvist et al. 2001, Wotton \& Malmqvist 2001, but see Monaghan et al. 2001). Blackfly fecal pellets travel hundreds of meters to kilometers downstream (Wotton et al. 1998, Malmquist et al. 2001), in extreme contrast to the highly localized deposition seen here for Atrina (and other cases studied in laboratory flumes, see citations below). Futhermore, biodeposit dispersal patterns in marine and estuarine environments will be more variable temporally and spatially in response to changes in tidal flows and 
wave-induced oscillatory flows. We expect that the scale of patchiness in the distribution of food resources around individuals or patches of Atrina will be influenced by both hydrodynamic conditions and by the topographic surface roughness of the downstream area.

Several previous studies have demonstrated passive accumulation of organic matter in relation to seafloor roughness or hydrodynamic baffling of the flow (Eckman 1979, van Blaricom 1982, Peterson et al. 1984, Snelgrove et al. 1993). Laboratory and field studies have shown that boundary flow conditions and sedimentation processes are modified around individual structures such as tubes (Eckman 1985), bivalves (Ertman \& Jumars 1988, Monismith et al. 1990), feeding pits (Yager et al. 1993), and over structures such as bivalve beds (Fréchette et al. 1989, O'Riordan et al. 1993, 1995, Green et al. 1998, Pilditch et al. 1998) and seagrass beds (Peterson et al. 1984, Peterson 1986, Nepf et al. 1997). Emergent structures, whether plant shoots, tubes or shells, cause near-bed flow to vary spatially (i.e. accelerate and decelerate) around the obstruction, and typically produces a volume of much reduced flow inside it. Decelerating flow results in concentration of suspended particles and enhanced deposition. Benthic fauna inhabiting these areas experience different flow and sedimentation dynamics than in adjacent regions. The net effect on larval and postlarval stages should depend on the balance of hydrodynamic (including baffling and sedimentation, Peterson et al. 1984) and biologically mediated process (growth, predation or settlement, Peterson 1986). However, the strength of many ecological effects will be modulated by the gradient of biodeposit dispersal and the structural roughness elements (Norkko et al. 2001).

We have demonstrated that biodeposit dispersal downstream of the horse mussel Atrina zelandica depends on the interaction between behavioral responses to the diet, and settling velocity and boundary layer flows. Biodeposits produced when silt was added to the diet had twice the settling velocity of those from the pure phytoplankton diet and were more likely to settle within the Atrina array. These effects altered the quality and quantity of biodeposits reaching the bed. We suggest that flow speed be varied in future studies and that experimental designs allow the detection of interactive effects between behavioral and physical factors. Such interactions should have strong, but localized effects on the incorporation of pelagic productivity into the sediments and their consequent impacts on benthic community structure.

Acknowledgements. We thank S. Thrush, J. Hewitt and V. Cummings (NIWA) for suggestions on an earlier version of this manuscript. Two anonymous reviewers and C. H. Peterson provided additional helpful comments. This study was supported by a grant to the National Institute of Water and Atmospheric Research (FRST COIXOO24). The School of Science \& Technology, University of Waikato, provided funding for the flume. We also acknowledge a sabbatical leave granted to the first author by the University of Delaware's Graduate College of Marine Studies, during which this research was conducted.

\section{LITERATURE CITED}

Commito JA, Boncavage EM (1989) Suspension-feeders and coexisting infauna: an enhancement counterexample. J Exp Mar Biol Ecol 125:33-42

Cummings VJ, Thrush SF, Hewitt JE, Turner SJ (1998) The influence of the pinnid bivalve Atrina zelandica (Gray) on benthic macroinvertebrate communities in soft-sediment habitats. J Exp Mar Biol Ecol 228:227-240

Cummings VJ, Thrush SF, Hewitt JE, Funnell GA (2001) The variable effect of a large suspension-feeding bivalve on infauna: experimenting in a complex system. Mar Ecol Prog Ser 209:159-175

Dame RF (1993) The role of bivalve filter-feeder material fluxes in estuarine ecosystems. In: Dame RF (ed) Bivalve filter feeders in estuarine and coastal ecosystem processes. NATO ASI series G: ecological sciences, Vol 33. Springer-Verlag, Berlin, p 245-269

Dame RF (1996) Ecology of marine bivalves. An ecosystem approach. CRC Press, Boca Raton

Dittmann S (1995) Benthos structure on tropical tidal flats of Australia. Helgol Meeresunters 49:539-551

Eckman JE (1979) Small-scale patterns and processes in a soft-substratum, intertidal community. J Mar Res 37: $437-457$

Eckman JE (1985) Flow perturbation by protruding animal tube affects rates of sediment microbial recolonization. J Mar Res 43:419-425

Eckman JE (1990) A model of passive settlement by planktonic larvae onto bottoms of differing roughness. Limnol Oceanogr 35:887-901

Eckman JE, Werner FE, Gross TF (1994) Modelling some effects of behavior on larval settlement in a turbulent boundary layer. Deep-Sea Res 41:185-208

Ertman SC, Jumars PA (1988) Effects of bivalve siphonal currents on the settlement of inert particles and larvae. J Mar Res 46:797-813

Finelli CM, Hart DM, Fonseca DM (1999) Evaluating the spatial resolution of an acoustic Doppler velocimeter and the consequences for measuring near-bed flows. Limnol Oceanogr 44:1793-1801

Finelli CM, Hart DM, Merz RA (2002) Stream insects as passive suspension feeders: effects of velocity and food concentration on feeding performance. Oecologia 131:145-153

Fonseca D (1999). Fluid mediated dispersal in streams: models of settlement from the drift. Oecologia 121:212-223

Fréchette M, Butman CA, Geyer WR (1989) The importance of boundary-layer flows in supplying phytoplankton to the benthic suspension feeder, Mytilus edulis L. Limnol Oceanogr 34:19-36

Gili JM, Coma R (1998) Benthic suspension feeders: their paramount role in littoral marine food webs. Trends Ecol Evol 13:316-321

Graf G, Rosenberg R (1997) Bioresuspension and biodeposition: a review. J Mar Syst 11:269-278

Grant J (1996) The relationship of bioenergetics and environment to field growth of cultured bivalves. J Exp Mar Biol Ecol 200:239-256 
Grassle JF (1989) Species diversity in deep-sea communities. Trends Ecol Evol 4:12-45

Green MO, Hewitt JE, Thrush SF (1998) Seabed drag coefficients over natural beds of horse mussels (Atrina zelandica). J Mar Res 56:613-637

Gross TF, Werner FE, Eckman JE (1992) Numerical modeling of larval settlement in turbulent bottom boundary layers. J Mar Res 50:611-642

Haven DS, Morales-Alamo R (1966) Aspects of biodeposition by oysters and other invertebrate filter feeders. Limnol Oceanogr 11:487-498

Iglesias JIP, Navarro E, Alvarez Jorna P, Armentia I (1992) Feeding, particle selection and absorption in cockles Cerastoderma edule (L.) exposed to variable conditions of food concentration and quality. J Exp Mar Biol Ecol 162: $177-198$

Jørgensen CB (1990) Bivalve filter feeding: hydrodynamics, bioenergetics, physiology and ecology. Olsen \& Olsen, Fredensborg

Kautsky N, Evans SE (1987). Role of biodeposition by Mytilus edulis in the circulation of matter and nutrients in a Baltic coastal ecosystem. Mar Ecol Prog Ser 38:201-212

Kraeuter JN (1976) Biodeposition by salt-marsh invertebrates. Mar Biol 35:215-223

Kroencke I (1996) Impact of biodeposition on macrofaunal communities in intertidal sandflats. PSZN I: Mar Ecol 17: 159-174

Lenihan HS, Peterson CH, Allen JM (1996) Does flow speed also have a direct effect on growth of active suspensionfeeders: an experimental test on oysters. Limnol Oceanogr 41:1359-1366

Malmqvist B, Wotton RS, Zhang Y (2001) Suspension feeders transform massive amounts of seston in large northern rivers. Oikos 92:35-43

Marsh AG, Tenore KR (1990) The role of nutrition in regulating the population dynamics of opportunistic, surface deposit feeders in a mesohaline community. Limnol Oceanogr 35:710-724

Mattsson J, Lindén O (1983) Benthic macrofauna succession under mussels, Mytilus edulis L. (Bivalvia), cultured on hanging long-lines. Sarsia 68:97-102

McNair JN (2000) Turbulent transport of suspended particles and dispersing benthic organisms: the hitting-time distribution for the local exchange model. J Theor Biol 202: 231-246

McNair JN, Newbold JD (2001) Turbulent transport of suspended particles and dispersing benthic organisms: the hitting-distance problem for the local exchange model. J Theor Biol 209:351-369

McNair JN, Newbold JD, Hart DD (1997) Turbulent transport of suspended particles and dispersing benthic organisms: how long to hit bottom? J Theor Biol 188:29-52

Monaghan MT, Thomas SA, Minshall GW, Newbold JD, Cushing CE (2001) The influence of filter-feeding benthic macroinvertebrates on the transport and depostion of particulate organic matter and diatoms in two streams. Limnol Oceangr 46:1091-1099

Monismith SG, Koseff JR, Thompson JK, O'Riordan CA, Nepf HM (1990) A study of model bivalve siphonal currents. Limnol Oceanogr 35:680-696

Muschenheim DK (1987) The dynamics of near-bed seston flux and suspension-feeding benthos. J Mar Res 45: 473-496

Muschenheim DK, Grant J, Mills EL (1986) Flumes for benthic ecologists: theory, construction and practice. Mar Ecol Prog Ser 28:185-196

Nepf HM, Sullivan JA, Zavistoski RA (1997) A model for dif- fusion within emergent vegetation. Limnol Oceanogr 42: 1735-1745

Newell RC, Field JG, Griffiths CL (1982) Energy balance and significance of microorganisms in a kelp bed community. Mar Ecol Prog Ser 8:103-113

Norkko A, Hewitt JE, Thrush SF, Funnell GA (2001) Benthicpelagic coupling and suspension feeding bivalves: linking site-specific sediment flux and biodeposition to benthic community structure. Limnol Oceanogr 46: 2067-2072

Nowell ARM, Jumars PA (1984) Flow environments of aquatic benthos. Annu Rev Ecol Syst 15:303-328

Nowell ARM, Jumars PA (1987) Flumes: theoretical and experimental considerations for simulation of benthic environments. Oceanogr Mar Biol Annu Rev 25:91-112

Nowell ARM, Jumars PA, Eckman JE (1981) Effects of biological activity on the entrainment of marine sediments. Mar Geol 42:133-153

Olafsson E (1992) Small-scale spatial distribution of marine meiobenthos: the effects of decaying macrofauna. Oecologia 90:37-42

O'Riordan, CA, Monismith SG, Koseff JR (1993) A study of concentration boundary layer formation over a bed of model bivalves. Limnol Oceanogr 38:1712-1729

O'Riordan CA, Monismith SG, Koseff JR (1995) The effect of bivalve excurrent jet dynamics on mass transfer in a benthic boundary layer. Limnol Oceanogr 40:330-344

Peterson CH (1986) Enhancement of Mercenaria mercenaria densities in seagrass beds: is pattern fixed during settlement season or altered by subsequent differential survival? Limnol Oceanogr 31:200-205

Peterson CH, Summerson HC, Duncan PB (1984) The influence of seagrass cover on population structure and individual growth rate of a suspension-feeding bivalve, Mercenaria mercenaria. J Mar Res 42:123-138

Pilditch CA, Emerson CW, Grant J (1998) Effect of scallop shells and sediment grain size on phytoplankton flux to the bed. Cont Shelf Res 17:1869-1885

Powell AWB (1979) New Zealand Mollusca. Marine, land and freshwater shells. William Collins, Auckland

Robinson WE, Langton RW (1980) Digestion in a subtidal population of Mercenaria mercenaria (Bivalvia). Mar Biol 58: 173-179

Roegner GC, Andre C, Lindegrath M, Eckman JE, Grant J (1995) Transport of recently settled soft-shelled clams (Mya arenaria L.) in laboratory flume flow. J Exp Mar Biol Ecol 187:13-26

Snelgrove PVR, Butman CA, Grassle JP (1993) Hydrodynamic enhancement of larval settlement in the bivalve Mulinia lateralis (Say) and the polychaete Capitella sp. I in microdepositional environments. J Exp Mar Biol Ecol 168: 71-109

Stoeck T, Albers BP (2000) Microbial biomass and activity in the vicinity of a mussel bed built up by the blue mussel Mytilus edulis. Helgol Mar Res 54:39-46

Taghon GL, Nowell, ARM, Jumars PA (1984) Transport and breakdown of fecal pellets: biological and sedimentological consequences. Limnol Oceanogr 29:64-72

Thrush SF, Hewitt JE, Pridmore RD (1989) Patterns in the spatial arrangements of polychaetes and bivalves in intertidal sandflats. Mar Biol 102:529-535

Thrush SF, Cummings VJ, Hewitt JE, Funnell GA, Green MO (2001) The role of suspension-feeding bivalves in influencing macrofauna: variations in response. In: Aller J, Aller R, Woodin SA (eds) Organism-sediment interactions. University of South Carolina Press, Columbia, SC, p 87-100 
van Blaricom GR (1982) Experimental analysis of structural regulation in a marine sand community exposed to oceanic swell. Ecol Monogr 52:283-305

Verwey J (1952) On the ecology and distribution of cockle and mussel in the Dutch Wadden Sea, their role in sedimentation and the source of their food supply. Arch Neerl Zool 10:172-239

Vogel S (1994) Life in moving fluids, 2nd edn. Princeton University Press, Princeton, NJ

Ward JE, MacDonald BA (1996) Pre-ingestive behaviors of two sub-tropical bivalves (Pinctada imbricata and Arca zebra): responses to an acute increase in suspended sediment concentration. Bull Mar Sci 59:417-432

Editorial responsibility: Charles Peterson (Contributing Editor), Morehead City, North Carolina, USA
Wildish D, Kristmanson D (1997) Benthic suspension feeders and flow. Cambridge University Press, Cambridge

Wotton RS, Malmqvist B (2001) Feces in aquatic ecosystems. BioScience 51:537-544

Wotton RS, Malmqvist B, Muotka T, Larsson K (1998) Fecal pellets from a dense aggregation of suspension-feeders in a stream: an example of ecosystem engineering. Limnol Oceanogr 43:719-725

Yager PL, Nowell ARM, Jumars PA (1993) Enhanced deposition to pits: a local food source for benthos. J Mar Res 51: 209-236

Zar JH (1984) Biostatistical analysis. Prentice-Hall, Englewood Cliffs, NJ

Submitted: July 27, 2001; Accepted: May 28, 2002

Proofs received from author(s): September 30, 2002 